\title{
Changes in Plasma Growth Differentiation Factor-15 After Laparoscopic Sleeve Gastrectomy in Morbidly Obese Patients: A Prospective Study
}

This article was published in the following Dove Press journal: Journal of Inflammation Research

\author{
Ahmed Salman (D) \\ Hossam El-Din Shaaban $\mathbb{D D}^{2}$ \\ Mohamed Salman ${ }^{3}$ \\ Sayed M Seif EI Nasr' \\ Ahmed Soliman' \\ Abdoh Salem ${ }^{4}$ \\ Mohamed Tag El-Din ${ }^{4}$ \\ Hani Maurice Sabri Mikhail ${ }^{3}$ \\ Heba El Domiaty ${ }^{5}$ \\ Nesrin Abd Allah ${ }^{6}$ \\ Ghada MK GabAllah ${ }^{7}$ \\ Ahmed Youssef' \\ 'Internal Medicine Department, Faculty \\ of Medicine, Cairo University, Cairo, \\ Egypt; ${ }^{2}$ Gastroenterology Department, \\ National Hepatology and Tropical \\ Medicine Research Institute, Cairo, Egypt; \\ ${ }^{3}$ General Surgery Department, Faculty of \\ Medicine, Cairo University, Cairo, Egypt; \\ ${ }^{4}$ General Surgery Department, Faculty of \\ Medicine, Al-Azhar University, Cairo, \\ Egypt; ${ }^{5}$ Clinical Physiology Department, \\ Faculty of Medicine, Menoufia University, \\ Shebin El-Kom, Menoufia, Egypt; \\ ${ }^{6}$ Anatomy and Embryology Department, \\ Faculty of Medicine, Menoufia University, \\ Shebin El-Kom, Menoufia, Egypt; ${ }^{7}$ Medical \\ Biochemistry Department, Faculty of \\ Medicine, Menoufia University, Shebin El- \\ Kom, Menoufia, Egypt
}

Correspondence: Ahmed Salman Internal Medicine Department, Faculty of Medicine, Cairo University, Cairo, Egypt Tel +201000468664

Email awea844@gmail.com
Purpose: This study aimed to assess the potential changes of Growth differentiation factor 15 (GDF15) after laparoscopic sleeve gastrectomy (LSG) in morbidly obese patients.

Methods: We conducted a prospective study on 68 patients who underwent LSG and 58 cases, who were enrolled as a control group, to whom conservative measures of weight loss were adopted. Both groups were followed for 12 months.

Results: At the baseline, the serum GDF15 was comparable between LSG and conservative groups ( $409.93 \pm 119$ versus $385.8 \pm 120.2 \mathrm{pg} / \mathrm{mL}, \mathrm{p}=0.246$ ). However, at 12 months after the operation, the serum GDF15 was significantly higher in the LSG than conservative groups $(699.941 \pm 193.5$ versus $559 \pm 159.7 ; \mathrm{p}<0.001)$. The degree of serum GDF15 increase was higher in the LSG group $(290.01 \pm 189.9$ versus $173.14 \pm 116.7$; $<0.001)$. The degree of serum GDF15 increase correlated negatively with the final BMI $(r=-0.352, p=0.001)$ and weight loss $(r=-0.793, p=0.001)$ at 12 months after the operation. The correlation analysis demonstrated that the initial GFD15 did not correlate with any baseline parameters. Multiple regression analysis of change in serum GDF15 showed a statistical significance of the weight loss after 12 months.

Conclusion: The present work confirms the impact of successful weight loss on the circulating level of GDF15. Our study demonstrated that the circulating GDF15 increased significantly after LSG and it was correlated to the degree of weight loss.

Keywords: bariatric surgery, laparoscopic sleeve gastrectomy, growth differentiation factor 15 , appetite

\section{Introduction}

Morbid obesity is associated with a high risk of metabolic disorder and cardiovascular disease mortality and morbidity. ${ }^{1-3}$ Due to poor outcomes of pharmacological and non-pharmacological approaches to morbid obesity, physicians have applied surgical procedures, which demonstrate incredibly high efficacy in severe, morbidly obese patients. ${ }^{4}$ Bariatric procedures induce significant weight loss with several changes in the mechanisms of homeostatic, including glucose and lipid homeostasis, and enhance the hormone regulation system. ${ }^{5}$ Anatomic alterations in the gastrointestinal tract can induce changes in gut hormones, bile acids, adipokines, inflammatory cytokines, hepatokines, and gut microbiota. Bariatric operations decrease pro-inflammatory molecules and enhance anti-inflammatory molecules. ${ }^{6}$

In the recent years, bariatric procedures played as gastrointestinal metabolic surgery has been viewed as a new strategy for obesity-associated type 2 diabetes 
mellitus (T2DM) for cases with BMI $>35 \mathrm{~kg} / \mathrm{m}^{2}$. Published data have shown that bariatric/metabolic surgery is an efficient and durable management option for obese T2DM subjects. ${ }^{7}$

Laparoscopic sleeve gastrectomy (LSG) is one of the most common restrictive bariatric surgery procedures, with more than $20 \%$ reduction in the original size of the stomach. ${ }^{8}$ For its simplicity, positive results and low complication rates, this technique is widely preferred. Some clinical trials for morbid obesity treatment have demonstrated better long-term survival after LSG than conventional care. ${ }^{9,10}$ Besides, it results in rapid and independent weight loss, T2DM remission and cardiovascular death reduction. ${ }^{11,12}$ LSG can improve glucose homeostasis in obese cases with T2DM through various mechanisms including the adipose tissue metalloproteinases $2,-7$, and -9 independent pathways. ${ }^{13}$ Other mechanisms for improvement include amelioration of insulin resistance (due to a substantial decrease in calorie intake, and decrease in fat mass) and postoperative elevated levels of gut hormones, such as glucagon-like peptide-1 that enhance cell response to nutrients. ${ }^{14}$

Growth differentiation factor (GDF-15), also called macrophage inhibitory cytokine-1 (MIC-1), is a novel inflammatory biomarker. It is considered one of the divergent TGF-beta family members. GDF-15 is induced in hepatocytes by surgical and chemical injury and heat shock. ${ }^{15,16}$

In healthy individuals, this marker circulates in the plasma with a detectable concentration, which elevates significantly in cancer patients. ${ }^{17,18}$ GDF15 has a significant role in the cases of cancer-related weight loss, as it induces fat and lean body mass loss. ${ }^{19}$ Moreover, it has been used as a prognostic biomarker to predict the mortality in patients with cardiovascular disease. ${ }^{20}$ Kempf et al and Vila et al reported that GDF15 is a promising predictor for impaired glucose control and future insulin resistance in morbidly obese patients. $^{21,22}$ However, the exact mechanism of GDF15 in obesity or the potential changes after bariatric surgeries is still unknown. Therefore, this study aimed to assess the potential changes of GDF15 after LSG in morbidly obese patients.

\section{Materials and Methods Study Design}

We conducted a prospective study on 68 patients who underwent LSG and 58 cases, who were enrolled as a control group, to whom conservative measures of weight loss were adopted. Both patients and controls were recruited from the period March 2016 to May 2018. All patients gave written informed consents. The responsible local Ethical Committee of Cairo University Hospitals approved this study. This study was conducted in accordance with the Declaration of Helsinki.

\section{Inclusion and Exclusion Criteria}

We enrolled only adult patients (18-65 years) who were underwent LSG and were willing to participate in this study. There were no gender restrictions. Patients with serious cardiac conditions, severe coagulopathy, untreated eating disorders, inability to fulfill the nutritional requirements, pregnancy, or unwillingness to participate in the study have been ruled out.

\section{Laparoscopic Sleeve Gastrectomy Procedure}

In all cases, we applied the standard LSG procedure. The procedure was conducted through four trocar-port $(5 \mathrm{~mm}$, $5 \mathrm{~mm}, 10 \mathrm{~mm}, 12 \mathrm{~mm}$ ). After inserting trocars, we used a Ligasure to split the greater omentum from the stomach. The first linear stapler was then fired at the beginning of a $4 \mathrm{~cm}$ from the gastroduodenal junction (Ethicon Echelon Flex Powered Endopath $60 \mathrm{~mm}$ ). Until the completion of the LSG, we inserted a gastric calibration tube (36-Fr bougie) into the stomach. To complete gastric resection, a total of 5 stapler firings were required. Finally, we used a Covidien 3-0 V-Loc suture with seromuscular suturing to reinforce the entire staple line.

\section{Determination of Obesity-Linked}

\section{Comorbidities}

The following criteria were adopted to determine the obesity-linked comorbidities. Diabetes was determined as the usage of antidiabetic drugs, fasting blood glucose $\geq$ $126 \mathrm{mg} / \mathrm{dL}$, or hemoglobin A1c (HbA1C) level $\geq 6.5 \%$. Hypertension was determined as the usage of antihypertensive drugs, systolic blood pressure $\geq 140 \mathrm{mmHg}$, or diastolic blood pressure $\geq 90 \mathrm{mmHg}$. Dyslipidemia was determined as the usage of lipid-lowering medications, total cholesterol $\geq 200 \mathrm{mg} / \mathrm{dL}$, triglycerides $\geq 200 \mathrm{mg} /$ $\mathrm{dL}$, or low-density lipoprotein cholesterol (LDLcholesterol) $\geq 120 \mathrm{mg} / \mathrm{dL}$. The occurrence of the disease at start of the study and at the end of follow-up was calculated according to these criteria with comparison between the two arms. ${ }^{23}$ 
Table I Characteristics of the Both Groups Prior to Intervention

\begin{tabular}{|c|c|c|c|}
\hline & Group I (LSG=68) & Group 2 (Conservative $=58$ ) & $P$ value \\
\hline Age (years) & $42 \pm 7.9$ & $38.76 \pm 8.3$ & $0.028 *$ \\
\hline \multicolumn{4}{|l|}{ Mean \pm SD } \\
\hline Male (Number, \%) & $34(50 \%)$ & $36(62.1 \%)$ & 0.174 \\
\hline Smoking (Number, \%) & $21(30.9 \%)$ & $14(24.1 \%)$ & 0.4 \\
\hline FH of CAD (Number, \%) & $5(7.4 \%)$ & $4(6.9 \%)$ & 0.92 \\
\hline Diabetes (Number, \%) & 19 (27.9\%) & $15(25.9 \%)$ & 0.79 \\
\hline Diabetics using insulin injections & $8(11.7 \%)$ & $7(12 \%)$ & 0.958 \\
\hline Hypertension (Number, \%) & 27 (39.7\%) & $16(27.6 \%)$ & 0.15 \\
\hline Hyperlipidemia (Number, \%) & $15(22.1 \%)$ & $12(20.7 \%)$ & 0.85 \\
\hline Obstructive Sleep Apnea (Number, \%) & II (I6.2\%) & $9(15.5 \%)$ & 0.92 \\
\hline COPD (Number, \%) & $6(8.8 \%)$ & $5(8.6 \%)$ & 0.96 \\
\hline $\mathrm{SBP}(\mathrm{mmHg}$, Mean $\pm \mathrm{SD})$ & $138.9 \pm 16.7$ & $137.4 \pm 17.4$ & 0.83 \\
\hline Height $(\mathrm{cm} /$ Mean $\pm \mathrm{SD})$ & $174.7 \pm 5.9$ & $177.4 \pm 6.2$ & $0.015^{*}$ \\
\hline Body Weight $(\mathrm{kg}$, Mean $\pm \mathrm{SD})$ & $136.67 \pm 1 \mid .6$ & $136.39 \pm 12.3$ & 0.89 \\
\hline BMI $\left(\mathrm{kg} / \mathrm{m}^{2}\right.$, Mean $\left.\pm \mathrm{SD}\right)$ & $44.8 \pm 3.5$ & $43.3 \pm 2.9$ & $0.011^{*}$ \\
\hline FBG $(\mathrm{mg} / \mathrm{dl}$, Mean $\pm \mathrm{SD})$ & $147.4 \pm 54.7$ & $148.3 \pm 59.2$ & 0.26 \\
\hline $\mathrm{FBI}(\mathrm{mlU} / \mathrm{mL}$, Mean $\pm \mathrm{SD})$ & $22.24 \pm 6.5$ & $23.6 \pm 7.1$ & 0.88 \\
\hline HbAIC (Mean \pm SD) & $6.3 \pm 1.3$ & $6.4 \pm 1.4$ & 0.74 \\
\hline HOMA-IR (Mean \pm SD) & $6.36 \pm 1.6$ & $5.48 \pm 1.6$ & $0.002^{*}$ \\
\hline Triglycerides (mg/dl, Median/lQR) & $138.9 \pm 16.7$ & $137.4 \pm 17.4$ & 0.15 \\
\hline T-Cholesterol (mg/dl, Median/IQR) & $206.8 \pm 45.4$ & $216.3 \pm 52.8$ & 0.28 \\
\hline LDL-C (mg/dl, Median/IQR) & $114.1 \pm 38.2$ & $132.93 \pm 41.9$ & $0.009 *$ \\
\hline ALT (U/L, Mean/SD) & $37.7 \pm 7.1$ & $30 \pm 5.3$ & $<0.001 *$ \\
\hline AST (U/L, Median/IQR) & $30.81 \pm 5.7$ & $33.36 \pm 6.1$ & $0.017^{*}$ \\
\hline
\end{tabular}

Note: *P value $<0.05$ significant.

Abbreviations: SBP, systolic blood pressure; FBG, fasting blood sugar; FPI, fasting plasma insulin; LDL, low density lipoproteins; ALT, alanine transaminase; AST, aspartate transaminase; BMI, body mass index.

Table 2 Follow-Up of the Metabolic Status Findings of Both Groups Post Intervention

\begin{tabular}{|c|c|c|c|}
\hline & Group I (LSG=68) & Group 2 (Conservative $=58$ ) & $P$ value \\
\hline Diabetes cured (Number, \%) & $10(14.7 \%)$ & 7 (12.1\%) & 0.76 \\
\hline Hypertension cured (Number, \%) & $17(25 \%)$ & $9(15.5 \%)$ & 0.32 \\
\hline Hyperlipidemia cured (Number, \%) & II (I6.2\%) & $7(12.1 \%)$ & 0.51 \\
\hline SBP $(\mathrm{mmHg}$, Mean \pm SD) & $119.40 \pm 10.9$ & $126 \pm 7.7$ & 0.122 \\
\hline Body Weight (kg, Mean \pm SD) & $98.52 \pm 8.8$ & $122.34 \pm 12.7$ & $<0.0001 *$ \\
\hline BMI $\left(\mathrm{kg} / \mathrm{m}^{2}\right.$, Mean $\left.\pm \mathrm{SD}\right)$ & $32.37 \pm 3.6$ & $38.84 \pm 3.3$ & $<0.0001 *$ \\
\hline Lost Weight $(\mathrm{Kg}$, Mean $\pm \mathrm{SD})$ & $38.1 \pm 12.2$ & $14.1 \pm 15.4$ & $<0.0001 *$ \\
\hline FBG $(\mathrm{mg} / \mathrm{dl}$, Mean \pm SD) & $100.29 \pm 26.4$ & I $37.8 \pm 49.4$ & $<0.000$ I* \\
\hline $\mathrm{FBI}(\mathrm{mlU} / \mathrm{mL}$, Mean $\pm \mathrm{SD})$ & $9.56 \pm 4.3$ & $16.14 \pm 6$ & $<0.0001 *$ \\
\hline HbAIC (Mean \pm SD) & $6.36 \pm 1.6$ & $5.48 \pm 1.6$ & $0.01 *$ \\
\hline HOMA-IR (Mean \pm SD) & $5.43 \pm 0.67$ & $5.86 \pm 1.1$ & $<0.0001^{*}$ \\
\hline Triglycerides (mg/dl, Mean \pm SD) & $153.7 \pm 22.2$ & $151.76 \pm 38.9$ & 0.72 \\
\hline T-Cholesterol $(\mathrm{mg} / \mathrm{dl}$, Mean $\pm \mathrm{SD})$ & $159.82 \pm 20.4$ & $166.12 \pm 35.8$ & 0.22 \\
\hline LDL-C (mg/dl, Mean \pm SD) & $78.26 \pm 16.6$ & $95.28 \pm 30.5$ & $<0.0001 *$ \\
\hline ALT (U/L, Mean $\pm S D)$ & $23.04 \pm 4.3$ & $27.97 \pm 5.2$ & $<0.0001 *$ \\
\hline AST (U/L, Mean $\pm S D)$ & $24.16 \pm 4.7$ & $30 \pm 6.5$ & $<0.0001 *$ \\
\hline
\end{tabular}

Note: *P value $<0.05$ significant.

Abbreviations: SBP, systolic blood pressure; FBG, fasting blood sugar; FPI, fasting plasma insulin; LDL, low-density lipoproteins; ALT, alanine transaminase; AST, aspartate transaminase; BMI, body mass index; HbAIC, hemoglobin AIC; HOMA-IR, homeostatic model assessment for insulin resistance. 


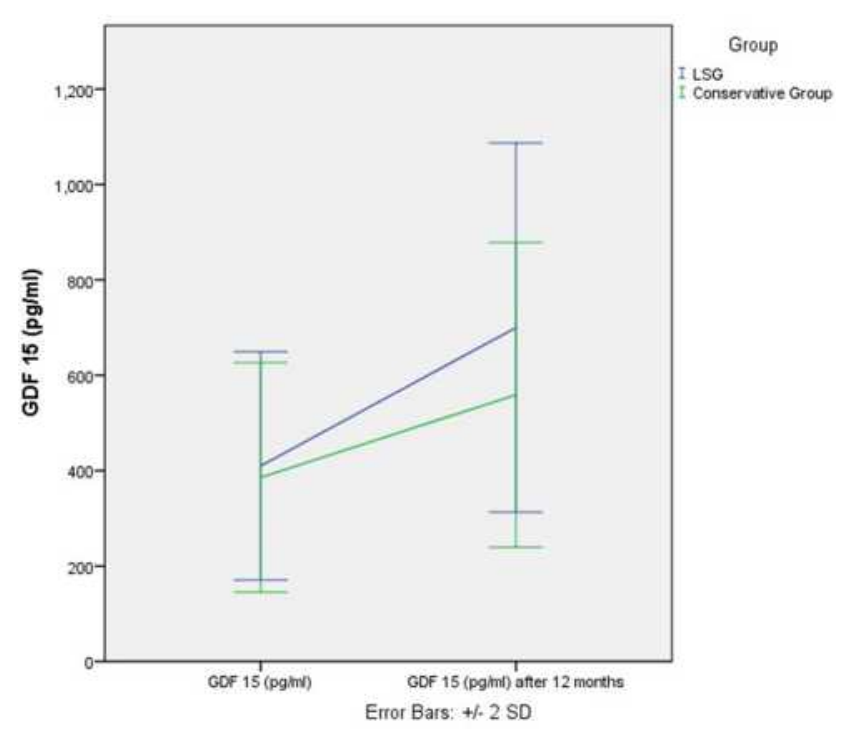

Figure I Degree of serum GDFI5 increase in both groups.

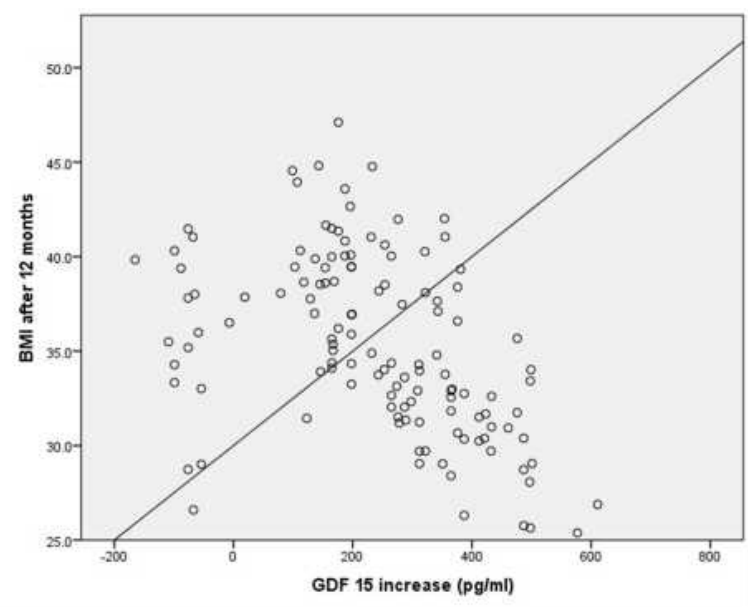

Figure 2 Correlation of degree of serum GDFI5 with the BMI.

\section{GDFI5 Assay}

Fasting blood was obtained in chilled, ethylenediaminetetraacetic acid (EDTA) tubes, for GDF15 assay. The serum was extracted at 80 Celsius for 10 minutes, after an immediate centrifuge at $3000 \mathrm{rpm}$, waiting for hormone analysis. The GDF15 assay was carried out using an enzyme-linked immunosorbent assay kit (ELISA; Cloud-Clone Corp, 1304 Langham Creek Dr, Suite 226, Houston, TX 77084 USA). The insulin resistance homeostasis (HOMA-IR) index was used for the calculation of insulin resistance [(Fasting Glucose-Fasting Insulin)/22.5.

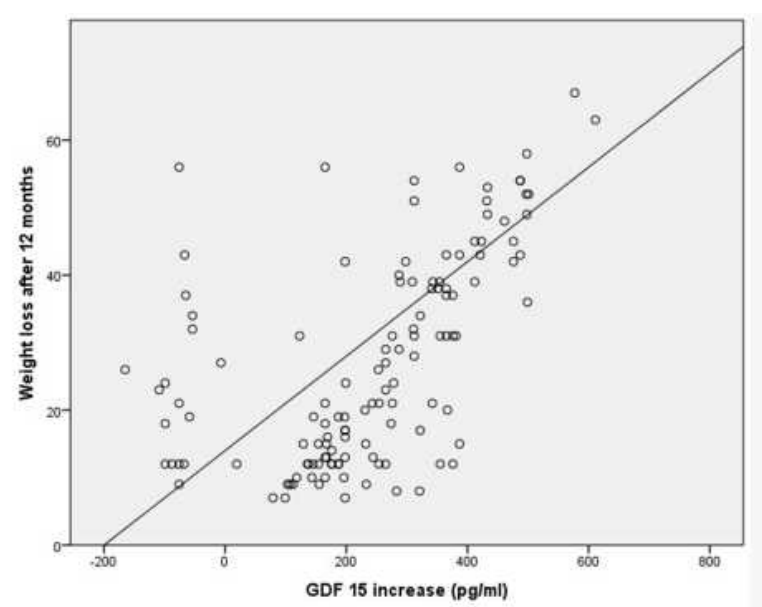

Figure 3 Correlation of degree of serum GDFI5 with the weight.

\section{Statistical Analysis}

Statistical analysis was performed using SPSS version 22. Categorical data were summarized using numbers and percentages. Continuous data were tested for normality using Kolmogorov-Smirnov test. Normally distributed variables were presented as mean and standard deviations, while variables that were not normally distributed were expressed as median and interquartile range. Chi-squared test was used to compare the categorical data and an independent $t$-test was used to compare continuous data. The correlation between the change in BMI with GDF15 was assessed using Pearson Correlation. P-value less than 0.05 was defined as significant and the null hypothesis was rejected.

Table 3 Correlation Between the Pre-Intervention Level of GFDI5 and Other Baseline Parameters

\begin{tabular}{|l|c|c|}
\hline Variable & r Coefficient & P-value \\
\hline Age & 0.074 & 0.41 \\
Weight & 0.014 & 0.87 \\
BMI & 0.165 & 0.07 \\
SBP & 0.131 & 0.56 \\
FBG & 0.022 & $0.8 I$ \\
FBI & -0.037 & 0.68 \\
HBAIC & -0.039 & 0.66 \\
HOMA-IR & 0.06 & 0.51 \\
Triglycerides & -0.040 & 0.65 \\
T-Cholesterol & -0.091 & 0.31 \\
LDL-C & -.0137 & 0.21 \\
ALT & 0.070 & 0.43 \\
AST & -0.151 & 0.92 \\
\hline
\end{tabular}


Table 4 Correlation of the Degree of Serum GDFI5 Increase and Change in Other Parameters

\begin{tabular}{|c|c|c|}
\hline & & GDFI5 Increase (pg/mL) \\
\hline \multirow[t]{3}{*}{ FPG change } & r & 0.211 \\
\hline & $P$ value & $0.018^{*}$ \\
\hline & $\mathrm{N}$ & 126 \\
\hline \multirow[t]{3}{*}{ FPI change } & r & 0.216 \\
\hline & $P$ value & $0.015^{*}$ \\
\hline & $\mathrm{N}$ & 126 \\
\hline \multirow[t]{3}{*}{ HOMA-IR change } & r & 0.199 \\
\hline & $P$ value & $0.025^{*}$ \\
\hline & $\mathrm{N}$ & 126 \\
\hline \multirow[t]{3}{*}{ Total-Cholesterol change } & $\mathrm{r}$ & $-0.007-$ \\
\hline & $P$ value & 0.935 \\
\hline & $\mathrm{N}$ & 126 \\
\hline \multirow[t]{3}{*}{ LDL-Cholesterol change } & $r$ & $-0.026-$ \\
\hline & $P$ value & 0.769 \\
\hline & $\mathrm{N}$ & 126 \\
\hline \multirow[t]{3}{*}{ Triglyceride change } & r & $-0.08 I-$ \\
\hline & $P$ value & 0.369 \\
\hline & $\mathrm{N}$ & 126 \\
\hline \multirow[t]{3}{*}{ ALT change } & $\mathrm{r}$ & 0.294 \\
\hline & $P$ value & $0.001 *$ \\
\hline & $\mathrm{N}$ & 126 \\
\hline \multirow[t]{3}{*}{ AST change } & r & 0.128 \\
\hline & $P$ value & 0.154 \\
\hline & $\mathrm{N}$ & 126 \\
\hline \multirow[t]{3}{*}{$\mathrm{HbAIC}$ change } & r & 0.124 \\
\hline & $P$ value & 0.166 \\
\hline & $\mathrm{N}$ & 126 \\
\hline
\end{tabular}

Note: *P value $<0.05$ significant.

Abbreviations: FBG, fasting blood sugar; FPI, fasting plasma insulin; LDL, lowdensity lipoproteins; ALT, alanine transaminase; AST, aspartate transaminase; BMI, body mass index; HbAIC, hemoglobin AIC; HOMA-IR, homeostatic model assessment for insulin resistance.

\section{Results}

The current study included 68 patients who underwent LSG. In addition, 58 cases were enrolled as a control group, to whom conservative measures of weight loss were adopted. The mean age in the LSG group was 42 \pm 7.9 years old compared to $38.76 \pm 8.3$ years old in the conservative group ( $\mathrm{p}=0.028$ ). The frequencies of smokers $(p=0.4)$, patients with history of coronary artery disease $(p=0.92)$, diabetes $(p=0.79)$, hypertension ( $p$ $=0.15)$, and hyperlipidemia $(\mathrm{p}=0.85)$ were comparable between both groups at the baseline. Patients in LSG group had significantly higher BMI than the conservative group ( $44.8 \pm 3.5$ versus $\left.43.3 \pm 2.9 \mathrm{Kg} / \mathrm{m}^{2} ; \mathrm{p}=0.011\right)$. Similarly, patients in LSG group had significantly higher homeostatic model assessment for insulin resistance (HOMA-IR) levels $(\mathrm{p}=0.002)$, serum ALT $(\mathrm{p}<0.001)$, and lower LDL-C $(p=0.009)$ than the control group. Other laboratory findings were comparable between both groups (Table 1).

At the end of follow-up, patients in LSG group exhibited significantly lower BMI than the conservative group ( $32.37 \pm 3.6$ versus $\left.38.84 \pm 3.3 \mathrm{Kg} / \mathrm{m}^{2} ; \mathrm{p}=0.001\right)$. Likewise, the extent of weight loss was significantly higher in the LSG group $(38.1 \pm 12.2$ versus $14.1 \pm 15.4 \mathrm{Kg}, \mathrm{p}=0.001)$. The values of HbAlc, fasting blood glucose, HOMA-IR, and LDL were significantly lower in the LSG group ( $p$ $>0.05$; Table 2).

At the baseline, the serum GDF15 was comparable between LSG and conservative groups (409.93 \pm 119 versus $385.86 \pm 120.2 \mathrm{pg} / \mathrm{mL}, \mathrm{p}=0.246$ ). However, at 12 months after the operation, the serum GDF15 was significantly higher in the LSG than conservative groups ( $699.941 \pm 193.5$ versus $559 \pm 159.7 ; p<0.001)$. The degree of serum GDF15 increase was higher in the LSG group ( $290.01 \pm 189.9$ versus $173.14 \pm 116.7 ; \mathrm{p}<0.001$; Figure 1 ). The degree of serum GDF15 increase correlated negatively with the final BMI $(\mathrm{r}=-0.352, \mathrm{p}=0.001)$ and weight loss $(r=-0.793, p=0.001)$ at 12 months after the operation (Figures 2 and 3 ).

The correlation analysis demonstrated that the initial GFD15 did not correlate with any baseline parameters (Table 3), while correlation between the change of serum GDF15 and change in other parameters showed significant correlation with FPG, fasting plasma insulin (FPI), HOMA-IR and ALT (Table 4).

Analysis of the relationship between change in serum GDF15 and change in each parameter in multiple regression analysis showed statistical significance of the weight loss after 12 months (Table 5).

As regards the LSG group, there was a significant correlation between changes in GDF15 and changes in weight and BMI (Table 6). The correlation with weight loss was more significant in the LSG group than the 
Table 5 Analysis of Relationship Between Change in Serum GDFI5 and Change in Each Parameter in Multiple Regression Analysis

\begin{tabular}{|c|c|c|c|c|c|c|c|c|}
\hline \multirow{2}{*}{\multicolumn{2}{|c|}{ Model }} & \multicolumn{2}{|c|}{$\begin{array}{l}\text { Unstandardized } \\
\text { Coefficients }\end{array}$} & \multirow{2}{*}{$\begin{array}{c}\begin{array}{c}\text { Standardized } \\
\text { Coefficients }\end{array} \\
\text { Beta }\end{array}$} & \multirow[t]{2}{*}{$\mathbf{t}$} & \multirow[t]{2}{*}{$\mathbf{P}$ value } & \multicolumn{2}{|c|}{$\begin{array}{l}\text { 95.0\% Confidence } \\
\text { Interval for B }\end{array}$} \\
\hline & & B & $\begin{array}{l}\text { Std. } \\
\text { Error }\end{array}$ & & & & $\begin{array}{l}\text { Lower } \\
\text { Bound }\end{array}$ & $\begin{array}{l}\text { Upper } \\
\text { Bound }\end{array}$ \\
\hline \multirow{7}{*}{$\begin{array}{l}\text { GDFI5 increase } \\
(\mathrm{pg} / \mathrm{mL})\end{array}$} & (Constant) & 95.798 & 193.286 & & 0.496 & 0.621 & $-286.926-$ & 478.523 \\
\hline & $\begin{array}{l}\text { Weight loss after } \\
12 \text { months }\end{array}$ & 6.556 & 1.512 & 0.595 & 4.337 & $<0.001 *$ & 3.563 & 9.550 \\
\hline & BMI after 12 months & $-0.77 I-$ & 4.617 & $-0.021-$ & $-0.167-$ & 0.868 & $-9.913-$ & 8.372 \\
\hline & FPG change & 0.343 & 0.346 & 0.084 & 0.992 & 0.323 & $-0.341-$ & 1.028 \\
\hline & FPI change & 1.500 & 2.557 & 0.052 & 0.587 & 0.558 & $-3.563-$ & 6.563 \\
\hline & HOMA-IR change & -10.345 & 9.045 & $-0.111-$ & $-1.144-$ & 0.255 & $-28.254-$ & 7.565 \\
\hline & ALT change & -1.409 & 2.080 & $-0.07 \mid-$ & $-0.677-$ & 0.500 & $-5.529-$ & 2.711 \\
\hline
\end{tabular}

Note: *P value $<0.05$ significant.

Abbreviations: FBG, fasting blood sugar; FPI, fasting plasma insulin; ALT, alanine transaminase; HbAIC, hemoglobin AIC; HOMA-IR, homeostatic model assessment for insulin resistance.

Table 6 Correlation Between Change in GDFI5 and Change in Weight and BMI Only in LSG Group

\begin{tabular}{|l|c|c|}
\hline \multicolumn{2}{|l|}{ LSG } & $\begin{array}{c}\text { GDF I5 Increase } \\
(\mathbf{p g / m L})\end{array}$ \\
\hline \multirow{3}{*}{ BMI after I2 months } & $r$ & $-0.366-$ \\
\cline { 2 - 3 } & P value & $0.002^{*}$ \\
\cline { 2 - 3 } & $\mathrm{N}$ & 68 \\
\hline $\begin{array}{l}\text { Weight loss after 12 } \\
\text { months }\end{array}$ & $\mathrm{r}$ & 0.535 \\
\cline { 2 - 3 } & $\mathrm{P}$ value & $<0.00 I^{*}$ \\
\cline { 2 - 3 } & $\mathrm{N}$ & 68 \\
\hline
\end{tabular}

Note: $* \mathrm{P}$ value $<0.05$ significant.

Abbreviation: BMI, body mass index.

Table 7 Correlation Coefficient of Change in GDFI5 with Change in Weight Between LGS and Conservative Groups

\begin{tabular}{|l|c|c|}
\hline \multicolumn{2}{|l|}{ Group 2 (Conservative) } & GDF I 5 Increase (pg/mL) \\
\hline Weight loss after I2 months & $r$ & 0.354 \\
\cline { 2 - 3 } & P value & $0.006^{*}$ \\
\cline { 2 - 3 } & $\mathrm{N}$ & 58 \\
\hline \multirow{2}{*}{ LSG } & & GDF I5 Increase (pg/mL) \\
\hline \multirow{2}{*}{ Weight loss after 12 months } & $\mathrm{r}$ & 0.535 \\
\cline { 2 - 4 } & $\mathrm{P}$ value & $<0.00 I^{*}$ \\
\cline { 2 - 3 } & $\mathrm{N}$ & 68 \\
\hline
\end{tabular}

Note: *P value $<0.05$ significant. conservative group (Table 7). Multi-regression analysis showed that the only independent predictor of GDF increase in LSG group was weight loss (Table 8).

\section{Discussion}

To date, the exact mechanism of GDF15 in obesity or the potential changes after bariatric surgeries is still unknown. In the current work, we showed that the GDF15 level increased significantly after LSG, the extent of GDF15 increase was significantly higher in patients who underwent LSG than patients who followed conservative treatment regimen. Notably, we found that the degree of change in GDF15 correlated significantly with the degree of weight loss and BMI 12 months after the operation.

GDF15 is a proinflammatory cytokine that presents at low level in various body organs; this cytokine is an important mediator whose level increases significantly during inflammatory process, tissue injury, ageing, and carcinogenesis. ${ }^{24}$ Moreover, a cumulative body of evidence demonstrated that circulating GDF15 is closely correlated with components of metabolic syndrome such as cardiovascular diseases, diabetes, and insulin resistance. ${ }^{23,25}$ Since the 2007 study by Johnen et $\mathrm{al}^{19}$ it has been shown that GDF15, through binding to (GDNF Family Receptor Alpha Like) GFRAL receptor in the brain stem, is a potent regulator of appetite as well; circulating GDF15 was found to induce anorexia, and weight loss in mice with 
Table 8 Multi-Regression Analysis for Factors Affecting Change in GDFI5 After LSG

\begin{tabular}{|c|c|c|c|c|c|c|c|c|}
\hline \multirow{2}{*}{\multicolumn{2}{|c|}{ Group I (LSG) }} & \multicolumn{2}{|c|}{$\begin{array}{l}\text { Unstandardized } \\
\text { Coefficients }\end{array}$} & \multirow{2}{*}{$\begin{array}{c}\begin{array}{c}\text { Standardized } \\
\text { Coefficients }\end{array} \\
\text { Beta }\end{array}$} & \multirow[t]{2}{*}{$\mathbf{t}$} & \multirow[t]{2}{*}{$P$ value } & \multicolumn{2}{|c|}{$\begin{array}{l}\text { 95.0\% Confidence } \\
\text { Interval for B }\end{array}$} \\
\hline & & B & $\begin{array}{l}\text { Std. } \\
\text { Error }\end{array}$ & & & & $\begin{array}{l}\text { Lower } \\
\text { Bound }\end{array}$ & $\begin{array}{l}\text { Upper } \\
\text { Bound }\end{array}$ \\
\hline \multirow{7}{*}{$\begin{array}{l}\text { GDFI5 increase } \\
(\mathrm{pg} / \mathrm{mL})\end{array}$} & (Constant) & -123.790 & 324.320 & & $-0.382-$ & 0.704 & $-772.307-$ & 524.728 \\
\hline & $\begin{array}{l}\text { Weight loss after } \\
12 \text { months }\end{array}$ & 8.307 & 2.210 & 0.534 & 3.758 & $<0.00 I^{*}$ & 3.887 & 12.727 \\
\hline & BMI after 12 months & $-0.660-$ & 7.402 & -0.013 & -0.089 & 0.929 & $-|5.46|-$ & 14.140 \\
\hline & FPG change & 0.487 & 0.449 & 0.119 & 1.085 & 0.282 & $-0.411-$ & 1.385 \\
\hline & FPI change & 4.499 & 5.343 & 0.091 & 0.842 & 0.403 & $-6.186-$ & 15.184 \\
\hline & HOMA-IR change & 7.060 & 15.746 & 0.049 & 0.448 & 0.655 & $-24.426-$ & 38.547 \\
\hline & ALT change & 1.034 & 2.956 & 0.038 & 0.350 & 0.728 & -4.878 & 6.946 \\
\hline
\end{tabular}

Note: $* \mathrm{P}$ value $<0.05$ significant.

overexpression of GDF15. ${ }^{26,27}$ Therefore, it seems logical to assume significant alterations in circulating GDF15 levels following any obesity-control measure; and that circulating GDF15 can be used as a proxy of the sensible weight loss and resolution of metabolic abnormalities. In the present study, we found that the serum GDF15 increased significantly following LSG to an extent that was higher than the increase following conservative management. In addition, degree of change in GDF15 correlated significantly with the degree of weight loss. Our findings are in line with a recent report by Dolo et $\mathrm{al}^{28}$ who demonstrated a significant increase in the circulating GDF15 levels after LSG. Another study showed that bariatric surgery significantly increase circulating GDF15 levels 12 months after surgery, this increase correlated significantly with weight loss. ${ }^{29}$ Another work showed similar findings. ${ }^{22}$

Nonetheless, it should be noted that the exact impact of circulating GDF15 on weight in human has not been fully understood yet with conflicting data. For example, contradictory to the results that demonstrated a regulatory role of GDF15 in response to obesity, previous study showed that overexpression of GDF15 following starvation, but not overfeeding. ${ }^{30}$ Therefore, further studies are still needed to highlight the role of GDF15 in feeding regulation.

In conclusion, the present work confirms the impact of successful weight loss on the circulating level of GDF15. Our study demonstrated that the circulating GDF15 increased significantly after LSG and it was correlated to the degree of weight loss. The current work could serve as a seminal study in the future, given the originality of the contribution and its clinically relevant nature. Most importantly, given the statistical results, the study underlines the fact that LSG has a measurable impact on plasma GDF15. Consequently, this shall reinforce the concept that the effects of LSG are primarily metabolic and physiological rather than merely anatomical/mechanistic.

\section{Novelty of the Study}

To our knowledge, scarce studies addressed the topic of the changes of GDF15 patients after LSG and so this article adds momentum to the literature regarding this novel topic. In addition, among the strengths of this study is the reasonable number of cases with a quite acceptable follow-up period. This point may make our work fairly unique as it is often difficult to get patients back for a second follow-up after such interval.

Furthermore, it is sensible to say that this work may point to potential mechanisms that may be underlying the weight loss after LSG and this shall provide novel horizons into the worth of GDF15; and possibly make it an attractive goal for new therapeutic approaches in disorders related to obesity.

\section{Author Contributions}

All authors contributed to data analysis, drafting or revising the article, have agreed on the journal to which the article will be submitted, gave final approval of the version to be published, and agree to be accountable for all aspects of the work. 


\section{Funding}

There is no funding to report.

\section{Disclosure}

The authors report no conflicts of interest for this work.

\section{References}

1. Abushouk AI, El-Husseny MWA, Bahbah EI, et al. Peroxisome proliferator-activated receptors as therapeutic targets for heart failure. Biomed Pharmacother. 2017;95:692-700. doi:10.1016/j.biopha.20 17.08.083

2. Pucci G, Alcidi R, Tap L, et al. Sex- and gender-related prevalence, cardiovascular risk and therapeutic approach in metabolic syndrome: a review of the literature. Pharmacol Res. 2017;120:34-42. doi:10.1016/j.phrs.2017.03.008

3. Milić S, Lulić D, Štimac D. Non-alcoholic fatty liver disease and obesity: biochemical, metabolic and clinical presentations. World J Gastroenterol. 2014;20(28):9330-9337. doi:10.3748/wjg.v20.i28.9330

4. Bennett JMH, Mehta S, Rhodes M. Surgery for morbid obesity. Postgrad Med J. 2007;83(975):8-15. doi:10.1136/pgmj.2006.048868

5. Dall'Asta C, Paganelli M, Morabito A, et al. Weight loss through gastric banding: effects on TSH and thyroid hormones in obese subjects with normal thyroid function. Obesity. 2010;18(4):854-857. doi:10.1038/oby.2009.320

6. Syu Y, Inui A, Chen C. A perspective on metabolic surgery from a gastroenterologist. J Pharmacol Sci. 2017;133(2):61-64. doi:10.10 16/j.jphs.2017.01.001

7. Lee WJ, Owaid Almalki O. Recent advancements in bariatric/metabolic surgery. Ann Gastroenterol Surg. 2017;1(3):171-179. doi:10. 1002/ags3.12030

8. Gentileschi P. Laparoscopic sleeve gastrectomy as a primary operation for morbid obesity: experience with 200 patients. Gastroenterol Res Pract. 2012;2012:1-4. doi:10.1155/2012/801325

9. Fuks D, Verhaeghe P, Brehant O, et al. Results of laparoscopic sleeve gastrectomy: a prospective study in 135 patients with morbid obesity. Surgery. 2009;145(1):106-113. doi:10.1016/j.surg.2008.07.013

10. Lombardo V, Baratta R, Giannone G. Laparoscopic sleeve gastrectomy for morbid obesity. Our initial experience. Ann Ital Chir. 2010;81(1):17-20.

11. Rosenthal RJ. International sleeve gastrectomy expert panel consensus statement: best practice guidelines based on experience of $>12,000$ cases. Surg Obes Relat Dis. 2012;8(1):8-19. doi:10.1016/j. soard.2011.10.019

12. Emadeldin D, Ramadan A, Fala SY, et al. Disease modifying efficacy of memantine in Alzheimer's disease; a pooled analysis of 13 randomized controlled trials. J Neurol Sci. 2017;381:767. doi:10.1016/j. jns.2017.08.2166

13. Wu W, Lee W, Lee T, Chen S, Chen C. Do different bariatric surgical procedures influence plasma levels of matrix metalloproteinase-2, -7 , and -9 among patients with type 2 diabetes mellitus? World J Diabetes. 2020;11(6):252-260. doi:10.4239/wjd.v11. i6.252

14. Wang Y, Song Y, Chen J, et al. Roux-en-Y gastric bypass versus sleeve gastrectomy for super super obese and super obese: systematic review and meta-analysis of weight results, comorbidity resolution. Obes Surg. 2019;29(6):1954-1964. doi:10.1007/s11695019-03817-4
15. Lerner L, Hayes TG, Tao N, et al. Plasma growth differentiation factor 15 is associated with weight loss and mortality in cancer patients. $J$ Cachexia Sarcopenia Muscle. 2015;6(4):317-324. doi:10.1002/jcsm. 12033

16. Zimmers TA, Jin X, Hsiao EC, McGrath SA, Esquela AF, Koniaris LG. Growth differentiation factor-15/macrophage inhibitory cytokine-1 induction after kidney and lung injury. Shock. 2005;23 (6):543-548.

17. Brown DA, Lindmark F, Stattin P, et al. Macrophage inhibitory cytokine 1: a new prognostic marker in prostate cancer. Clin Cancer Res. 2009;15(21):6658-6664. doi:10.1158/1078-0432.CCR08-3126

18. Meyer-Siegler KL, Bellino MA, Tannenbaum M. Macrophage migration inhibitory factor evaluation compared with prostate specific antigen as a biomarker in patients with prostate carcinoma. Cancer. 2002;94(5):1449-1456. doi:10.1002/cncr.10354

19. Johnen H, Lin $S$, Kuffner $T$, et al. Tumor-induced anorexia and weight loss are mediated by the TGF- $\beta$ superfamily cytokine MIC1. Nat Med. 2007;13(11):1333-1340. doi:10.1038/nm1677

20. Schopfer DW, Ku IA, Regan M, et al. Growth differentiation factor 15 and cardiovascular events in patients with stable ischemic heart disease (The Heart and Soul Study). Am Heart J. 2014;167(2):186192.e1. doi:10.1016/j.ahj.2013.09.013

21. Kempf T, Guba-Quint A, Torgerson J, et al. Growth differentiation factor 15 predicts future insulin resistance and impaired glucose control in obese nondiabetic individuals: results from the XENDOS trial. Eur J Endocrinol. 2012;167(5):671-678. doi:10.1530/EJE-120466

22. Vila G, Riedl M, Anderwald C, et al. The relationship between insulin resistance and the cardiovascular biomarker growth differentiation factor-15 in obese patients. Clin Chem. 2011;57(2):309-316. doi:10.1373/clinchem.2010.153726

23. Park JY, Yoonseok Heo Y, Kim YJ, et al. Long-term effect of bariatric surgery versus conventional therapy in obese Korean patients: a multicenter retrospective cohort study. Ann Surg Treat Res. 2019;96(6):283-289. doi:10.4174/astr.2019.96.6.283

24. Fairlie WD, Moore AG, Bauskin AR, et al. MIC-1 is a novel TGF- $\beta$ superfamily cytokine associated with macrophage activation. J Leukoc Biol. 1999;65(1):2-5. doi:10.1002/jlb.65.1.2

25. Lind L, Wallentin L, Kempf T, et al. Growth-differentiation factor-15 is an independent marker of cardiovascular dysfunction and disease in the elderly: results from the Prospective Investigation of the Vasculature in Uppsala Seniors (PIVUS) study. Eur Heart J. 2009;30(19):2346-2353. doi:10.1093/eurheartj/ehp261

26. Wakchoure S, Swain TM, Hentunen TA, et al. Expression of macrophage inhibitory cytokine- 1 in prostate cancer bone metastases induces osteoclast activation and weight loss. Prostate. 2009;69 (6):652-661. doi:10.1002/pros.20913

27. Hsu JY, Crawley S, Chen M, et al. Non-homeostatic body weight regulation through a brainstem-restricted receptor for GDF15. Nature. 2017;550(7675):255-259. doi:10.1038/nature24042

28. Dolo PR, Yao L, Liu PP, et al. Effect of sleeve gastrectomy on plasma growth differentiation factor-15 (GDF15) in human. Am J Surg. 2020;220(3):725-730. doi:10.1016/j.amjsurg.2020.01.041

29. Kleinert M, Bojsen-Møller KN, Jørgensen NB, et al. Effect of bariatric surgery on plasma GDF15 in humans. Am J Physiol Metab. 2019;316:E615-E621.

30. Patel S, Alvarez-Guaita A, Melvin A, et al. GDF15 provides an endocrine signal of nutritional stress in mice and humans. Cell Metab. 2019;29(3):707-718.e8. doi:10.1016/j.cmet.2018.12.016 


\section{Publish your work in this journal}

The Journal of Inflammation Research is an international, peerreviewed open-access journal that welcomes laboratory and clinical findings on the molecular basis, cell biology and pharmacology of inflammation including original research, reviews, symposium reports, hypothesis formation and commentaries on: acute/chronic inflammation; mediators of inflammation; cellular processes; molecular mechanisms; pharmacology and novel anti-inflammatory drugs; clinical conditions involving inflammation. The manuscript management system is completely online and includes a very quick and fair peerreview system. Visit http://www.dovepress.com/testimonials.php to read real quotes from published authors.

Submit your manuscript here: https://www.dovepress.com/journal-of-inflammation-research-journal 